\title{
Anti-Müllerian hormone and progesterone levels produced by granulosa cells are higher when derived from natural cycle IVF than from conventional gonadotropin-stimulated IVF
}

\author{
Zahraa Kollmann ${ }^{1 *}$, Nick A Bersinger ${ }^{1,2}$, Brett D McKinnon ${ }^{2}$, Sophie Schneider ${ }^{1}$, Michael D Mueller ${ }^{1}$
} and Michael von Wolff'

\begin{abstract}
Background: The study was designed to compare the effect of in vitro FSH stimulation on the hormone production and gene expression profile of granulosa cells (GCs) isolated from single naturally matured follicles obtained from natural cycle in vitro fertilization (NC-IVF) with granulosa cells obtained from conventional gonadotropin-stimulated IVF (c-IVF).
\end{abstract}

Methods: Lutein granulosa cells from the dominant follicle were isolated and cultured in absence or presence of recombinant FSH. The cultures were run for $48 \mathrm{~h}$ and six days. Messenger RNA (mRNA) expressions of anti-Müllerian hormone $(\mathrm{AMH})$ and FSH receptor were measured by quantitative polymerase chain reaction (qPCR). AMH protein and progesterone concentration (P4) in cultured supernatant were measured by ELISA and RIA.

Results: Our results showed that the mRNA expression of AMH was significantly higher in GCs from NC- than from c-IVF on day 6 after treatment with FSH (1 IU/mL). The FSH stimulation increased the concentration of AMH in the culture supernatant of GCs from NC-IVF compared with cells from c-IVF. In the culture medium, the AMH level was correlated significantly and positively to progesterone concentration.

Conclusions: Differences in the levels of AMH and progesterone released into the medium by cultured GC as well as in $\mathrm{AMH}$ gene expression were observed between GCs obtained under natural and stimulated IVF protocols. The results suggest that artificial gonadotropin stimulation may have an effect on the intra-follicular metabolism. A significant positive correlation between $\mathrm{AMH}$ and progesterone may suggest progesterone as a factor influencing AMH secretion.

Keywords: Human granulosa cells, Natural cycle, Anti-Müllerian hormone, Follicle-stimulating hormone receptor, Progesterone, IVF

\section{Background}

Follicle growth is a complex process involving a functioning and bidirectional communication between each oocyte and its surrounding somatic cell compartments [1-3]. At the antral stage of follicular growth most follicles undergo atresia, although due to gonadotropin stimulation, some will enter the pre-ovulatory stage [4-6]. However, the exact

\footnotetext{
* Correspondence: zahraa.kollmann@insel.ch

'Department of Obstetrics and Gynecology, Inselspital Berne, Berne University Hospital, Effingerstrasse 102, 3010 Berne, Switzerland Full list of author information is available at the end of the article
}

mechanism of follicle selection and primordial follicle activation is not yet completely understood.

The follicle-stimulating hormone (FSH) and its receptor (FSHR) play an essential role in recruitment and follicle growth $[7,8]$. In humans the dominant follicle selection may depend on differential FSH sensitivity amongst a growing cohort of small antral follicles. Various growth factors related to the TGF $\beta$ superfamily contribute to this selection process by interacting with gonadotropin-induced signals [9-11]. Anti-Müllerian hormone (AMH) is one such growth factor that is produced by granulosa cells (GCs) 
and present in small and large pre-antral follicles, with maximal levels observed in secondary, preantral and small antral follicles $\leq 4 \mathrm{~mm}$ [7]. AMH may play an important role in primordial follicle selection and cyclic growing follicle recruitment [12]. Moreover, AMH might regulate the selection of the dominant follicle through the inhibitory effects of AMH on the initial recruitment of primary follicles from the resting primordial follicle pool [13-15] and through the regulation of FSH, sensitivity in the human ovary [16].

In addition, recent research has suggested a relationship exists between follicular fluid AMH concentrations of the pre-ovulatory follicle and the occurrence of a clinical pregnancy. Embryo implantation rates were higher when oocytes were obtained from follicles with high $\mathrm{AMH}$ concentrations in the follicular fluid, but not in the serum on cycle day 3 and on the day of oocyte pickup $[17,18]$. Furthermore, it has been shown that follicular AMH concentrations were approximately three-fold higher in NC-IVF follicles than in c-IVF-follicles at the time of ovum pickup [19]. In addition, previous studies have shown that the implantation potential of oocytes is higher in NC-IVF [20,21] compared with c-IVF [22], and it can be expected that the NC-IVF follicles would closely represent physiologically normal follicles. Thus it can be assumed that the artificial stimulation of follicle growth that occurs in c-IVF treatment has certain effects on the follicles. In the context of a project studying the difference and clinical consequences between natural and stimulated IVF treatment cycles with different approaches, we have decided to set up a series of in vitro experiments to assess the endocrine function of GCs derived from both NC-IVF and c-IVF protocols. This was done by measuring the AMH production and secretion and the progesterone (P4) secretion by cultured granulosa cells both with and without FSH stimulation.

\section{Methods}

\section{Study population and treatment cycles}

The study was approved by the local ethical committee before commencement (reference no. 12-023, Inselspital Berne, Teaching and Research Management, IRB Internal Review Board, approved 11 October 2012) and patients' approval was given by written consent.

GCs were collected at oocyte retrieval from 41 women (mean age $36.5+/-3.8(\mathrm{SD})$, range 28-42) and with regular cycles who had been referred to our clinic for infertility treatment between October 2012 and August 2013. The study population was divided into two groups according to the selected treatment protocol. (A) Patients $(\mathrm{n}=21)$ undergoing NC-IVF without medical intervention except for the administration of hCG (Pregnyl; MSD, Switzerland) $36 \mathrm{~h}$ before follicle aspiration and (B) patients $(n=20)$ undergoing a stimulation cycle (c-IVF) with GnRH antagonist (Orgalutran, Ganirelix 0,25 mg, MSD, Switzerland) protocol and using highly purified hMG (Menopur, Menotropin hMG, Ferring Pharmaceuticals, Baar, Switzerland) for 8-10 days and daily doses of 150-300 IU of hMG, followed by hCG (Pregnyl). Transvaginal ultrasound guided oocyte retrieval was performed $36 \mathrm{~h}$ later. In c-IVF, granulosa cells were collected from the first aspirated matured (MII) large follicle (LF; > = $18 \mathrm{~mm}$ ). The causes of infertility were mainly male or idiopathic in both groups; the individual numbers are given in Table 1.

\section{Collection and culture of granulosa cells}

Immediately after oocyte retrieval and the isolation of the cumulus oophorus complex, granulosa cells were isolated from the follicular fluid and flushing medium [23]. Only the leading follicle was analysed in stimulated cycles without pooling. The total aspirate volume was collected in a 15-ml polystyrene test tube (BD Falcon) and centrifuged at $440 \times g$ for $10 \mathrm{~min}$. The GCs containing pellets were clearly visible and were separated, avoiding aggregates with red blood cells as described elsewhere [24], with the exception of the density gradient, which had to be omitted due to the small number of GCs present in single follicles. The Pellets were suspended in $0.4 \mathrm{~mL}$ freezing medium (Iscove's modified Dulbecco medium, IMDM, Gibco-Ivitrogen, Paisley, Scotland) without phenol red and with DMSO $(10 \% \mathrm{v} / \mathrm{v})$ and stored at $-80^{\circ} \mathrm{C}$ until used in the culture experiment. To ensure that sufficient GC populations had been obtained in the flushing procedure, a direct smear slide was made from the pellet for each sample. The smear slides were prepared by cytocentrifugation, fixed immediately with Cytostat $400^{\circ}$ spray (Simat AG, Glattbrugg, Switzerland) and stained with Papanicolau (PAP) reagent [25].

For the culture experiment the isolated GCs were thawed at $37^{\circ} \mathrm{C}$ and washed twice in culture medium (IMDM containing foetal bovine serum $(10 \% \mathrm{v} / \mathrm{v})$, penicillin,

\section{Table 1 Study population and ovarian cycle} characteristics

\begin{tabular}{llll}
\hline Variables & $\begin{array}{l}\text { Group A } \\
\text { NC-IVF }\end{array}$ & $\begin{array}{l}\text { Group B } \\
\text { clVF }\end{array}$ & P \\
\hline Patients & 21 & 20 & $\mathrm{~ns}$ \\
Age, mean +/- SEM (yrs) & $35.4+/-0.8$ & $37.6+/-0.8$ & $\mathrm{~ns}$ \\
Range & $28-41$ & $31-42$ & \\
Etiology of infertility (n/Total) & $7 / 21$ & $8 / 20$ & \\
Male factor & & & \\
Tubal factor & $4 / 21$ & $2 / 20$ & \\
Endometriosis & $4 / 21$ & $2 / 20$ & \\
Idiopathic & $6 / 21$ & $8 / 20$ & \\
AMH (pmol/L) & $14.2+/-3.7$ & $22.4+/-5.1$ & 0.1430 \\
Number of oocytes retrieved & $1.0+/-0.0$ & $6.9+/-1.2$ & $<0.0001^{* * *}$ \\
Follicle Diameter (mm) & $18.2+/-0.4$ & $18.5+/-0.4$ & $\mathrm{~ns}$ \\
\hline
\end{tabular}

Data other than $P$ values are mean $+/-$ SEM. 
streptomycin and Fungizone (all from Gibco-Invitrogen) and without phenol red. Cells were counted with Trypan blue for evaluation of cell concentration and viability, then seeded at 10,000 live cells $/ \mathrm{cm}^{2}$ into 48-well plates and maintained in complete medium with foetal bovine serum and the antibiotic/antimycotic reagent. After $24 \mathrm{~h}$ of incubation in $1 \mathrm{ml}$ total volume, the supernatants were then aspirated and medium containing recombinant FSH (Gonal- $\mathrm{F}^{\circ}$, $0.1 \mathrm{IU} / \mathrm{mL}$ or $1.0 \mathrm{IU} / \mathrm{mL}$, Merck Serono S.A., Geneva, Switzerland) was added. One well from each sample was cultured as a control in the absence of FSH. The cultures were run for $48 \mathrm{~h}$ and six days. For the measurement of progesterone and $\mathrm{AMH}$ protein concentrations, $0.5 \mathrm{ml}$ of supernatant was removed from each well after $48 \mathrm{~h}$ and the remaining volume on day 6 at conclusion of the culture. Supernatants were centrifuged at $1000 \times g$ for 5 min. Progesterone (P4) was quantified using a commercially available radio-immunoassay ("Coat-a-Count") from DPC, Los Angeles, USA. The 3-h incubation protocol at room temperature was used. For P4 determinations the introduced supernatant volume had to be diluted 1:5 in the zero standard as a carrier. The intra-assay coefficient of variance at the relevant $\mathrm{P} 4$ concentrations was between 3.6 and $4.9 \%$. AMH was determined manually with commercially available specific microplate Enzyme-Linked Immunosorbent Assay (ELISA). The assay for AMH was obtained from Cusabio (China). The functional sensitivity of the assay was $0.375 \mathrm{ng} / \mathrm{mL}$, and the intra- and interassay coefficients of variance were reported to be $15 \%$ each. Culture supernatants were diluted $1: 2$ in $0.9 \% \mathrm{NaCl}$ prior to assay and the protocol of the manufacturer was followed. The hormone concentrations were expressed after normalisation by dividing their concentration by the cell number.

\section{Immunofluorescence staining of granulosa cells for FSH receptor}

Granulosa cells were identified by the expression of the FSH receptor (FSHR). They were plated on cover slips at 10,000 live cells $/ \mathrm{cm}^{2}$ into 48-well plates. After six days of culture, cells were fixed in paraformaldehyde $(4 \% \mathrm{w} / \mathrm{v}$, Grogg Chemie, Stettlen, Switzerland) for $10 \mathrm{~min}$. and rinsed five times in PBS containing Tween-20 $(0.1 \% \mathrm{v} / \mathrm{v}$, PBST). The slides were incubated with the primary antibody against FSH receptor (monoclonal mouse antihuman FSHR, R\&D Systems, England, dilution 1:50), 5\% normal goat serum (NGS), $0.5 \%$ casein, in PBS for $90 \mathrm{~min}$. at room temperature After three washes in PBST, the slides were incubated with the second antibody, chicken antimouse IgG $(\mathrm{H}+\mathrm{L})$ labelled with Alexa ${ }^{\circ}$ Fluor 488 (Invitrogen, USA, dilution 1:200) for $1 \mathrm{~h}$ at room temperature. Then, the slides were washed another three times in PBST. Nuclei were stained with 4,6-diamidinmo-2-phenylindole (DAPI, sigma) at a final concentration of $0.5 \mu \mathrm{g} / \mathrm{mL}$ for
$10 \mathrm{~min}$. and washed three times for $10 \mathrm{~min}$. in PBST before mounting in UltraCruz ${ }^{\mathrm{m}}$ Mounting Medium sc-24941 (Santa Cruz Biotechnology Inc.). Fluorescence images were captured under an Axiovert $40 \mathrm{CFL}$ with AxioCam MRm.

\section{Determination of gene expression}

Samples with a useful quantity of RNA were extracted from 14 single follicles (NC-IVF) out of $n=21$. Another 14 samples were collected from the c-IVF group with a total number of 20 samples. Extraction of RNA was achieved by using the Rneasy ${ }^{\circ}$ Plus Micro Kit (Qiagen, Hilden, Germany) according to the manufacturer's protocol. RNA quantity and purity were determined with a Nanodrop ${ }^{\circ}$ Spectrophotometer (Wilmington, USA). Reverse transcription (RT) was performed with the Quantitech Reverse Transcription kit (Qiagen, Hilden, Germany) with a concentration of $0.15 \mathrm{ng} /$ $\mu \mathrm{L}$ RNA in $20 \mu \mathrm{L}$. A pre-amplification of cDNA was performed using TaqMan ${ }^{\circ}$ PreAmp Master Mix Kit (AB, Applied Biosystems, CA, USA) for 14 cycles, as recommended by the manufacturer. The subsequent cDNA was used for quantitative PCR (qPCR) in $20 \mu \mathrm{L}$ reaction volumes using the TaqMan ${ }^{\circ}$ Gene Expression assays (Applied Biosystems Europe, Zug, Switzerland), in an Applied Biosystems 7900 HT Fast Real Time PCR System. The following primers/ probes were used: AMH (NM_000479, Hs01006984); FSHR (NM_000145, Hs00174865); with GAPDH (NM_002046, Hs03929097) and ACTB (NM_001101, Hs00242273) as reference genes.

The relative gene expression was calculated with the qBASEplus software (Biogazelle, Zwijnaarde, Belgium) using a method based on the $\Delta \Delta C t$ method that incorporates the use of multiple reference genes.

\section{Statistical analysis}

All statistical analyses were performed using GraphPad Prism. The non-parametric Mann-Whitney U-test was performed to compare the expression of mRNA between the GCs from the cIVF group and cells from NC-IVF. For analysis of variance, the two-way ANOVA test was used to compare the effect of IVF method and the effect of FSH treatment. The Spearman Rank Correlation Analysis was applied to determine whether there was a significant relationship between progesterone and AMH concentrations in the culture medium. The significance level was set at $\mathrm{p}<0.05$. All data are expressed as the mean $+/-$ SEM.

\section{Results}

The clinical parameters in NC-IVF and c-IVF patients are summarized in Table 1. There were no differences in patient age, AMH level in serum or follicle diameter between treatment groups. 


\section{Cell morphology}

In the PAP staining method nuclei appear as homogeneously dark blue chromatin whereas the cytoplasm appears as a pale eosinophilic coloration (Figure 1A).

Human granulosa cells in culture attached within $24 \mathrm{~h}$, the red blood cells were visible in the initial culture, but did not remain after gentle shaking and a change of the media after $24 \mathrm{~h}$ of culture. The FSHR in the GCs were identified using immunostaining on day 6 . Cells cultured and treated with FSH $(0.1 \mathrm{IU} / \mathrm{ml}, 1 \mathrm{IU} /$ $\mathrm{mL}$ ) have shown a fibroblast-like morphology and an intracellular signal for FSHR (Figure 1C, D).

\section{Effect of FSH on the expression of follicle stimulating receptor and of AMH mRNA}

NC-IVF GCs stimulated for six days with $1 \mathrm{IU} / \mathrm{mL}$ FSH had a significantly higher AMH mRNA expression compared with c-IVF GCs $(3.41+/-1.55, \mathrm{n}=14$ vs. $0.053+/-0.43$, $\mathrm{n}=14 ; p=0.0344$ ) (Figure 2A). There was no significant difference in the expression of FSHR mRNA $(4.76+/-4.06$, $\mathrm{n}=14$ vs. $10.34+/-5.82, \mathrm{n}=14)$ in cells obtained from $\mathrm{NC}$ or c-IVF after $1 \mathrm{IU} / \mathrm{mL}$ FSH (Figure 2B).

\section{Effect of FSH on AMH protein levels in the culture media of GCs}

The mean AMH concentration in the conditioned medium from GCs derived from NC-IVF in the absence of FSH showed no significant difference from the mean AMH concentration from the c-IVF GCs after $48 \mathrm{~h}$ culture $(12.9+/-1.2, \mathrm{n}=21$ vs. $5.8+/-2.5 \mathrm{ng} / 10,000$ cells, $\mathrm{n}=20$ ). While after $1 \mathrm{IU} / \mathrm{mL} \mathrm{FSH}$ treatment at $48 \mathrm{~h}$ there was a significant difference between the NC-IVF and c-IVF GCs $(47.4+/-4.2, \mathrm{n}=21$ vs. $8.7+/-3.0 \mathrm{ng} /$ $10,000$ cells, $n=20)$. FSH $(1 \mathrm{IU} / \mathrm{mL})$ increased the AMH concentration in the culture medium of GCs from NCIVF significantly $(p=0.0201)$ when compared with control group without FSH. Moreover, the level of AMH was significant higher in treated GCs from NC-IVF with FSH $(1 \mathrm{IU} / \mathrm{mL})$ when compared with treated GCs from c-IVF ( $p=0.0046)$ (Figure 3A). After six days of culture, both the unstimulated (control groups) and $1 \mathrm{IU} / \mathrm{mL}$ FSH-stimulated GCs groups did not exhibit a significant difference between the NC-IVF and the c-IVF, see (Figure 3B). In the control group from NC-IVF and c-IVF, the concentration of AMH was $(18.1+/-2.9$, $\mathrm{n}=21$ vs. $14.8+/-1.8 \mathrm{ng} / 10,000$ cells, $\mathrm{n}=20)$. In the
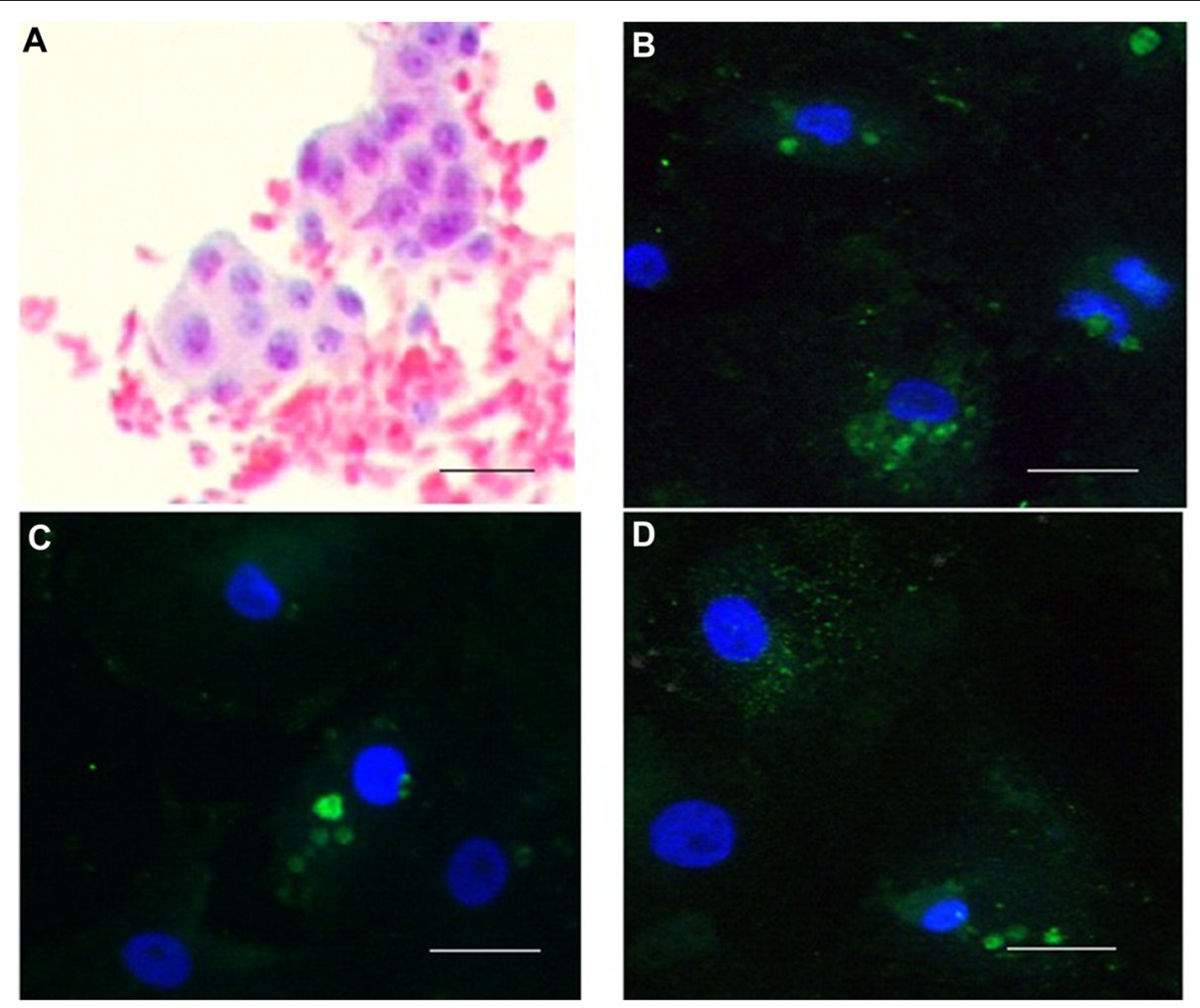

Figure 1 Staining for Granulosa cells and Immunofluorescence staining for FSH receptor. (A) Aggregated granulosa cells stained with Papanicolaou (20x magnification). Bar $=20 \mu \mathrm{m}$. Localisation of FSH receptor (FSHR) in human granulosa cells (GC) after six days in culture, Immunofluorescence FSHR staining with monoclonal mouse anti-human FSHR (primary), chicken anti-mouse (Alexa, secondary), counterstained with DAPI for nuclei. (B) GCs in control culture (without FSH) showing cytoplasmic vesicles; (C) GC culture stimulated with FSH $0.1 \mathrm{IU} / \mathrm{mL}$ showing outgrowth with fibroblast-like morphology; (D) GC culture stimulated with FSH $1 \mathrm{IU} / \mathrm{mL}$ showing an intracellular signal for FSHR which could indicate de novo production (40x magnification). Bar $=40 \mu \mathrm{m}$. 

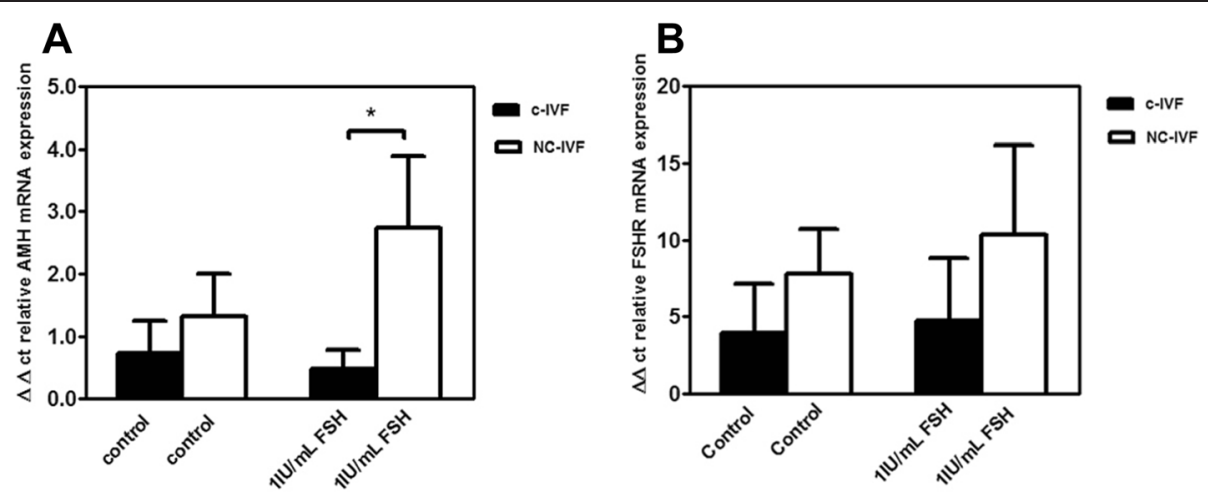

Figure 2 Effect of FSH on the expression of FSHR- and of AMH- mRNA in GCs from NC-IVF and c-IVF. Gene expression of AMH mRNA (panel A) and FSHR mRNA (panel B) levels by qPCR in the granulosa cell lysate after six days of culture in 28 GC preparations ( $N C$-IVF, $N=14$, open bars; c-IVF, $N=14$, closed bars).

FSH-stimulated group, the concentration of $\mathrm{AMH}$ in NC-IVF decreased after six days, but it remained slightly higher than in c-IVF $(28.1+/-8.0, \mathrm{n}=21$ vs. $20.9+/-$ $4.0 \mathrm{ng} / 10,000$ cells, $\mathrm{n}=20)$.

\section{Effect of FSH on progesterone concentration in the culture media of GCs}

A higher but non-significant increase in $\mathrm{P} 4$ was observed in the GCs from NC-IVF compared with c-IVF $(188.0+/-$ $60.1, \mathrm{n}=21$ vs. $119.0+/-20.7 \mathrm{pmol} / 10,000$ cells, $\mathrm{n}=20$ ) after a 48-h treatment with $1 \mathrm{IU} / \mathrm{mL}$ FSH (Figure 4A). On day 6, P4 showed a similar pattern of increasing, but it was not significant in the culture medium from NC-IVF GCs compared with c-IVF GCs in the presence of $1 \mathrm{IU} / \mathrm{mL}$ FSH $(201.0+/-93.3, \mathrm{n}=21$ vs. $101.09+/-19.3 \mathrm{pmol} /$ 10,000 cells, $n=20$ ) (Figure 4B). A significant positive correlation after six days of treatment with $1 \mathrm{IU} / \mathrm{mL}$ FSH between Progesterone and AMH concentrations from both NC-IVF GCs $(\mathrm{r}=0.89, p<0.0001)$ and from c-IVF GCs $(\mathrm{r}=0.64, p=0.014)$ was observed.

\section{Discussion}

The objective of this study was to compare the GCs obtained from c-IVF and NC-IVF by analyzing the production of both progesterone and $\mathrm{AMH}$ and their subsequent responsiveness to FSH exposure in vitro. The results indicate that both groups of GCs retain FSHR, the expression of which can be further induced by FSH treatment. The NC-IVF GCs, however, produced significantly more AMH mRNA and secreted significantly more AMH upon FSH exposure. In addition, a six-day FSH treatment of both groups resulted in the secretion of more $\mathrm{P} 4$ from the $\mathrm{NC}$ IVF cells compared with the c-IVF cells. The results of this study therefore suggest that GCs from NC-IVF retain a higher sensitivity to FSH compared with GCs from c-IVF. It is therefore possible that c-IVF stimulation may result in GCs reaching their peak progesterone production capabilities during the stimulatory cycle.

A major finding of this study is the increased AMH mRNA expression in GCs from NC-IVF after a six-day FSH $(1 \mathrm{IU} / \mathrm{mL})$ treatment. Previous studies on the relationship
A

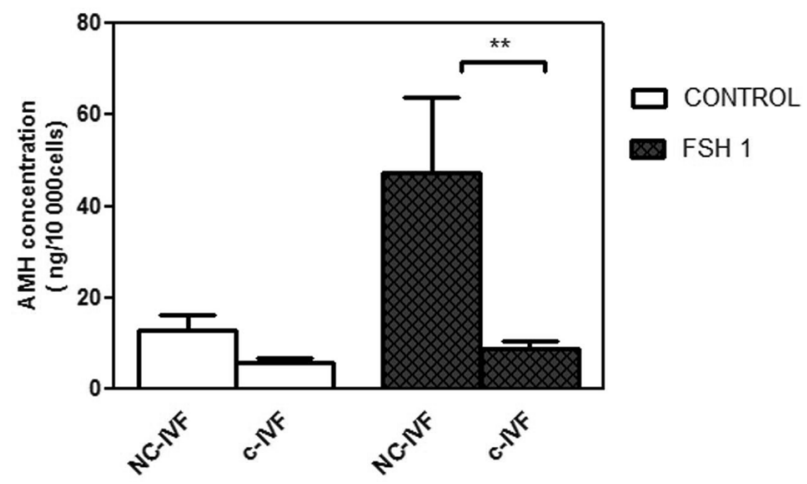

B

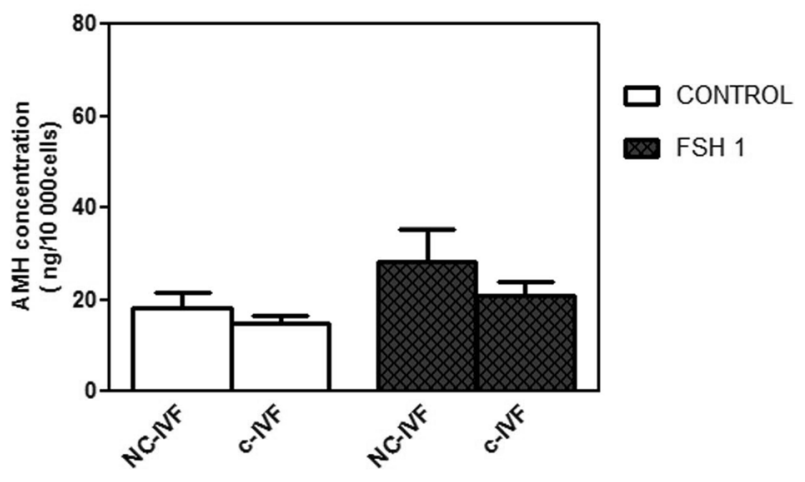

Figure 3 Effect of FSH on AMH concentrations in the culture media of GCs from NC-IVF and c-IVF. Comparison of AMH concentrations in the culture medium of granulosa cells (GCs) isolated from conventionally stimulated IVF (c-IVF, N=20) and from natural cycle IVF (NC-IVF, $N=21)$, cultured in absence (control, open bars) and presence of FSH (1.0 IU/mL, closed bars). Incubation in culture was $48 \mathrm{~h}$ (Graph A) and 6 days (Graph B). Data are presented as the mean +/- SEM. 


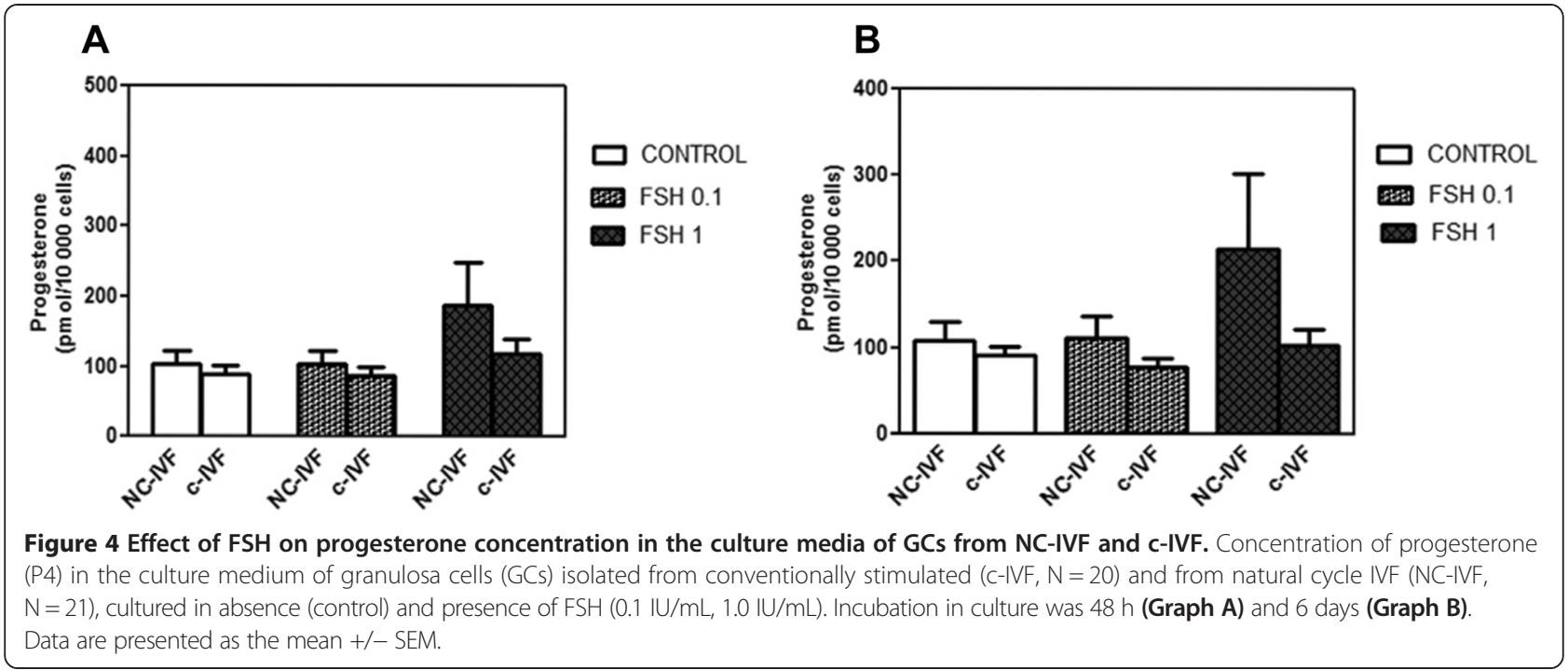

between FSH and AMH in GC cultures have been inconsistent. Taieb et al. [26] showed that both FSH and cAMP upregulated AMH mRNA expression in human luteinized GCs, whereas Pellatt et al. [27] did not detect any effect of FSH on AMH production by GCs derived from normal ovaries, but in GCs from women with polycystic ovaries FSH stimulation decreased significantly AMH levels. A further study also reported a FSH-stimulated AMH increase in GCs from both normo-ovulatory and oligo/anovulatory PCOS women [28]. The observations from this latter group support our results and suggest that elevated AMH secretion in cultured GCs from NC-IVF would not depend on the previous production of the hormone in small antral follicles.

GCs from NC-IVF also showed a significant increase in in vitro secretion of $\mathrm{AMH}$ after $48 \mathrm{~h}$ exposure to $1 \mathrm{IU} / \mathrm{mL} \mathrm{FSH}$. After six days this increase in AMH secretion from NC-IVF compared with c-IVF was still present, however the higher variation between the different culture preparations may have hindered the analysis of statistical significance. Our results from both protein (Figure 3) and gene expression (Figure 2A) for $\mathrm{AMH}$ show the same trend as previously reported for the follicular fluid concentrations of the same hormone [19] although statistical significance was not reached in the absence of FSH stimulation in vitro. The expression of the FSH receptor and the effects of FSH stimulation vary throughout the different stage of GC differentiation [29]. The mechanism of how gonadotropins affect AMH secretion in GC is not clear, although it is possible that the follicular and the luteal phases have differing dynamics [30,31].

Another finding which we consider important was that after a six-day culture, $\mathrm{P} 4$ concentrations were increased in NC-IVF compared with the c-IVF after $1 \mathrm{IU} / \mathrm{mL}$ FSH and that $\mathrm{AMH}$ secretion was correlated with $\mathrm{P} 4$ concentrations in the both groups but especially strongly in the NC-IVF group. The long incubation time has been initially chosen in order to reach a higher sensitivity for both the absolute hormone levels in the supernatant and for the difference in these levels between the different hormone treatments. A shorter, potentially more physiologically relevant incubation period would have been difficult to control for technical reasons.

P4 is the major steroid synthesized by luteinized GCs [32], and it is therefore possible that the luteinization of GCs changes the follicular capacity to produce AMH. Previous evidence shows that the level of P4 declines during final follicular maturation [33,34], and the degree of this maturation and luteinization may influence AMH production by the GCs [30]. It has also been shown that the serum and follicular levels of AMH decline immediately after hCG administration but rise again four days later [30]. Similarly, it has been reported that in natural IVF cycles an alteration in the hormonal milieu after the LH surge increases serum AMH levels on the day of follicle aspiration, which reflects early pre-ovulatory changes after hCG administration [31]. Therefore, these results suggest that c-IVF results in lower concentrations of AMH secreted from GCs. A number of reasons for this reduced production and secretion are possible: First, c-IVF is characterized by the growth of several follicles following multiple follicle recruitment during the initial stimulation step compared with NC-IVF. It can be speculated that the non-physiological recruitment of multiple follicles results in intrinsic abnormalities in the ovarian follicles themselves and in relation to the numbers of recruited and aspirated follicles. This is suggested by several studies that investigated follicular and serum AMH 
levels after stimulation with menopausal and recombinant gonadotropins [35-37]. Second, an exogenous gonadotropin administration during the follicular phase would correlate with a decrease of AMH secretion. A study which compared the changes of serum AMH levels between spontaneous cycles and FSH treated cycles during the follicular phase did not find a change in AMH plasma levels in the spontaneous cycles, but did find a change in $\mathrm{AMH}$ plasma levels in the FSH treated cycles [38].

A minor limitation of the current study is the use of human lutein GCs. This is not the best model to study the regulation of $\mathrm{AMH}$ by gonadotropins because these cells have been exposed to exogenous hCG administration. Because of this exposure to hCG administration, in vitro studies do not perfectly reflect the in vivo situation during follicular maturation. However, progesterone production is an accepted marker for $\mathrm{GC}$ responsiveness to $\mathrm{FSH}$ stimulation.

\section{Conclusions}

Our study has shown that luteinized granulosa cells obtained on the day of oocyte retrieval after either c-IVF or NC-IVF react differently to FSH stimulation in vitro. GCs from NC-IVF retain their physiological capacity to respond to FSH stimulation by increasing their production and secretion of $\mathrm{AMH}$ and progesterone. Moreover, the reduced $\mathrm{AMH}$ production of GCs obtained from c-IVF follicles suggests that for future research, treatment with exogenous gonadotropins might force the production of oocytes even from non-competent follicles. If an adaption of the stimulation protocols in c-IVF could improve the intrafollicular metabolism and thereby increases the oocyte quality, remains to be evaluated.

\section{Competing interests}

The authors are clinically involved in low dose mono-follicular stimulation and IVF-therapies, using gonadotropins from all gonadotropin distributors on the Swiss market, including Institut Biochimique SA and MSD Merck Sharp \& Dohme $\mathrm{GmbH}$.

\section{Authors' contributions}

ZK participated in the design of the study, analysis and the interpretation of data and wrote the manuscript. NAB participated in the design of the study, the interpretation of data and helped to draft the manuscript. BDM helped in the molecular biological methods and critically revised the manuscript. SS and MDM participated in the interpretation of data and revised the manuscript. MWW participated in its design, coordination and helped to draft the manuscript. All authors read and approved the final manuscript.

\section{Acknowledgements}

The study was supported by a restricted research grant from IBSA Institut Biochimique SA and MSD Merck Sharp \& Dohme GmbH. We thank Ms. Anne Vaucher for her skillful laboratory assistance with the cell cultures and molecular biological methods.

\section{Author details}

${ }^{1}$ Department of Obstetrics and Gynecology, Inselspital Berne, Berne University Hospital, Effingerstrasse 102, 3010 Berne, Switzerland. ${ }^{2}$ Department of Clinical Research, University of Berne, Murtenstrasse 35, 3010 Berne, Switzerland
Received: 2 July 2014 Accepted: 6 March 2015

Published online: 24 March 2015

\section{References}

1. Eppig JJ. Oocyte control of ovarian follicular development and function in mammals. Reproduction. 2001;22:829-38.

2. Matzuk MM, Burns KH, Viveiros MM, Eppig JJ. Intercellular communication in the mammalian ovary: oocytes carry the conversation. Science. 2002;296:2178-80.

3. Gilchrist RB, Lane M, Thompson JG. Oocyte-secreted factors: regulators of cumulus cell function and oocyte quality. Hum Reprod Update. 2008;14:159-77.

4. Gougeon A. Regulation of ovarian follicular development in primates: facts and hypotheses. Endocr Rev. 1996;17:121-55.

5. Hirshfield AN. Development of follicles in the mammalian ovary. Int Rev Cytol. 1991;124:43-101.

6. Hsueh AJ, McGee EA, Hayashi M, Hsu SY. Hormonal regulation of early follicle development in the rat ovary. Mol Cell Endocrinol. 2000;163:95-100.

7. Weenen C, Laven JS, Von Bergh AR, Cranfield M, Groome NP, Visser JA, et al. Anti-Müllerian hormone expression pattern in the human ovary: potential implications for intial and cyclic recruitment. Mol Hum Reprod. 2004;10:77-83.

8. Nordhoff V, Sonntag B, von Tils D, Götte M, Schüring AN, Gromoll J, et al. Effects of the FSH receptor gene polymorphism p.N680S on CAMP and steroid production in cultured primary human granulosa cells. Reprod Biomed Online. 2001;23:196-203.

9. Knight PG, Glister C. TGF-beta superfamily members and ovarian follicle development. Reproduction. 2006;132:191-206.

10. Glister C, Satchell L, Knight PG. Granulosal and thecal expression of bone morphogenetic protein- and activin-binding protein mRNA transcripts during bovine follicle development and factors modulating their expression in vitro. Reproduction. 2011;142:581-91.

11. Yding Andersen C, Rosendahl M, Byskov AG. Concentration of anti-Müllerian hormone and inhibin-B in relation to steroids and age in follicular fluid from small antral human follicles. J Clin Endocrinol Metab. 2008;93:2344-49.

12. Carlsson IB, Scott JE, Visser JA, Ritvos O, Themmen AP, Hovatta O. Anti-Müllerian hormone inhibits initiation of growth of human primordial ovarian follicles in vitro. Hum Reprod. 2006;21:2223-27.

13. Durlinger AL, Gruijters MJ, Kramer P, Karels B, Kumar TR, Matzuk MM, et al. Anti-Müllerian hormone attenuates the effects of FSH on follicle development in the mouse ovary. Endocrinology. 2001;142:4891-99.

14. Visser JA, Themmen APN. Anti-Müllerian hormone and folliculogenesis. Mol Cell Endocrinol. 2005;234:81-6.

15. Broekmans FJ, Visser JA, Laven JSE, Broer SL, Themmen APN, Fauser BC. Anti-Müllerian hormone and ovarian dysfunction. Trends Endocrinol Metab. 2008;19:340-7.

16. Kevenaar ME, Themmen AP, Laven JS, Sonntag B, Fong SL, Uitterlinden AG, et al. Anti-Müllerian hormone and anti-Müllerian hormone type II receptor polymorphisms are associated with follicular phase estradiol levels in normo-ovulatory women. Hum Reprod. 2007;22:1547-54.

17. Fanchin R, Mendez Lozano DH, Frydman N, Gougeon A, di Clemente N, Frydman R, et al. Anti-Müllerian hormone concentrations in the follicular fluid of the preovulatory follicle are predictive of the implantation potential of the ensuing embryo obtained by in vitro fertilization. J Clin Endocrinol Metab. 2007;92:1796-802.

18. Takahashi C, Fujito A, Kazuka M, Sugiyama R, Ito H, Isaka K. Anti-Müllerian hormone substance from follicular fluid is positively associated with success in oocyte fertilization during in vitro fertilization. Fertil Steril. 2008;89:586-91.

19. von Wolff M, Kollmann Z, Flück CE, Stute P, Marti U, Weiss B, et al. Gonadotrophin stimulation for in vitro fertilization significantly alters the hormone milieu in follicular fluid: a comparative study between natural cycle IVF and conventional IVF. Hum Reprod. 2014;29:1049-57.

20. Schimberni M, Morgia F, Colabianchi J, Giallonardo A, Piscitelli C, Giannini P, et al. Natural-cycle in vitro fertilization in poor responder patients: a survey of 500 consecutive cycles. Fertil Steril. 2009;92:1297-301.

21. Gordon JD, DiMattina M, Reh A, Botes A, Celia G, Payson M. Utilization and success rates of unstimulated in vitro fertilization in the United States: an analysis of the Society for Assisted Reproductive Technology database. Fertil Steril. 2013;100:392-5.

22. Ferraretti AP, Goossens V, de Mouzon J, Bhattacharya S, Castilla JA, Korsak V, et al. Assisted reproductive technology in Europe, 2008: results generated 
from European registers by ESHRE. European IVF-monitoring (EIM); Consortium for European Society of Human Reproduction and Embryology (ESHRE). Hum Reprod. 2012;27:2571-84.

23. Von Wolff M, Hua YZ, Santi A, Ocon E, Weiss B. Follicle flushing in monofollicular in vitro fertilization almost doubles the number of transferable embryos. Acta Obstet Gynecol Scand. 2013;92:346-8.

24. Kossowska-Tomaszczuk K, de Geyter CM, de Geyter M, Martin I, Holzgreve W, Scherberich A. The multipotency of luteinizing granulosa cells collected from mature ovarian follicles. Stem Cells. 2009;27:210-9.

25. Carson FL, Hladik C. Histotechnology: A Self-Instructional Text. 3rd ed. Hong Kong: American Society for Clinical Pathology Press; 2009. p. 361-3.

26. Taieb J, Grynberg M, Pierre A, Arouche N, Massart P, Belville C, et al. FSH and its second messenger CAMP stimulate the transcription of human anti-Müllerian hormone in cultured granulosa cells. Mol Cell Endocrinol. 2011;25:645-55.

27. Pellatt L, Hanna L, Brincat M, Galea R, Brain H, Whitehead S, et al. Granulosa cell production of anti-Müllerian hormone is increased in polycystic ovaries. J Clin Endocrinol Metab. 2007;92:240-5.

28. Pierre A, Peigné M, Grynberg M, Arouche N, Taieb J, Hesters L, et al. Loss of LH-induced down-regulation of anti-Mullerian hormone receptor expression may contribute to anovulation in women with polycystic ovary syndrome. Hum Reprod. 2013;28:762-9.

29. Lindeberg M, Carlström K, Ritvos O, Hovatta O. Gonadotrophin stimulation of non-luteinized granulosa cells increases steroid production and the expression of enzymes involved in estrogen and progesterone synthesis. Hum Reprod. 2007;22:401-6.

30. Fanchin R, Louafi N, Lozano M, Frydman N, Frydman R, Taieb J. Per-follicle measurements indicate that anti-müllerian hormone secretion is modulated by the extent of follicular development and luteinization and may reflect qualitatively the ovarian follicular status. Fertil Steril. 2005;84:167-73.

31. Lee JR, Kim SH, Kim SM, Jee BC, Ku S-Y, Suh CS, et al. Anti-Mullerian hormone dynamics during controlled ovarian hyperstimulation and optimal timing of measurement for outcome prediction. Hum Reprod. 2010;25:2597-604.

32. Songsasen N, Woodruff TK, Wildt DE. In vitro growth and steroidogenesis of dog follicles are influenced by the physical and hormonal microenvironment. Reproduction. 2001;142:113-22.

33. Vigier B, Picard JY, Tran D, Legeai L, Josso N. Production of anti-Müllerian hormone: another homology between Sertoli and granulosa cells. Endocrinology. 1984;114:1315-20

34. Baarends WM, Hoogerbrugge JW, Post M, Visser JA, De Rooij DG, Parvinen $M$, et al. Anti-müllerian hormone and anti-müllerian hormone type ॥ receptor messenger ribonucleic acid expression during postnatal testis development and in the adult testis of the rat. Endocrinology. 1995;136:5614-22.

35. Andersen CY, Byskov AG. Estradiol and regulation of anti-Müllerian hormone, inhibin-A, and inhibin-B secretion: Analysis of small antral and preovulatory human follicles' fluid. J Clin Endocrinol Metab. 2006;91:4064-9.

36. Smitz J, Andersen AN, Devroey P, Arce J-C, MERIT Group. Endocrine profile in serum and follicular fluid differs after ovarian stimulation with HP-hMG or recombinant FSH in IVF patients. Hum Reprod. 2007;22:676-87.

37. Anckaert E, Smitz J, Schiettecatte J, Klein BM, Arce J-C. The value of anti-Mullerian hormone measurement in the long GnRH agonist protocol: association with ovarian response and gonadotrophin-dose adjustments. Hum Reprod. 2012;27:1829-39.

38. Marca AL, Malmusi S, Giulini S, Tamaro LF, Orvieto R, Levratti P, et al. Anti-Müllerian hormone plasma levels in spontaneous menstrual cycle and during treatment with FSH to induce ovulation. Hum Reprod. 2004;19:2738-41.

\section{Submit your next manuscript to BioMed Central and take full advantage of:}

- Convenient online submission

- Thorough peer review

- No space constraints or color figure charges

- Immediate publication on acceptance

- Inclusion in PubMed, CAS, Scopus and Google Scholar

- Research which is freely available for redistribution

Submit your manuscript at www.biomedcentral.com/submit 